\title{
A NEW MYCOPLASMA SPECIES ISOLATED FROM PNEU- MONIC LUNGS OF CALVES (MYCOPLASMA DISPAR SP. NOV.)
}

\author{
R. N. Gourlay and R. H. Leach
}

ARC Institute for Research on Animal Diseases, Compton, Newbury, Berkshire, and Mycoplasma Reference Laboratory, Central Public Health Laboratory, Colindale Avenue, London

\section{Plates VIII-X}

TYPICAL large-colony mycoplasmas are prevalent in the upper respiratory tract of normal cattle and in the lungs of calves with pneumonia (Davies, 1967; Günther et al., 1967; Leach, 1967) and mycoplasma T-strains have also been isolated from the latter source (Gourlay, 1968).

These organisms can be cultivated by the use of the appropriate conventional mycoplasma medium, but such media are not suitable for cultivation of all types of mycoplasma, and several mycoplasmas found in animals require special media for primary isolation. A relevant example is the mycoplasma causing enzootic pneumonia in pigs, named Mycoplasma hyopneumoniae (Mare and Switzer, 1965) or Mycoplasma suipneumoniae (Goodwin, Pomeroy and Whittlestone, 1965). This organism can be cultivated in a special acellular medium modified from tissue-culture fluids, but cannot be grown in conventional mycoplasma medium of the type described by Chanock, Hayflick and Barile (1962).

This suggested that there might be unrecognised mycoplasmas in other animals, and that they might be detected by the use of similar media. With this in mind we used a modification of the medium of Goodwin et al. (1965) in attempts to isolate mycoplasmas from the lungs of calves, as part of a current microbiological and pathological investigation of calf pneumonia at Compton. Strains of an unusual type of organism were isolated in this medium. They have the general characteristics of mycoplasmas, but with some atypical features, and do not appear to have been described before. A preliminary report on the isolation of these organisms has been published (Gourlay, 1969).

\section{MATERIALS AND METHODS}

Culture media. For the attempted isolation and growth of mycoplasmas from calf lungs, the following glucose calf-serum (GS) broth was normally used: Hanks' buffered salt solution (Burroughs Wellcome and Co.) $40 \mathrm{ml}$; lactalbumin hydrolysate (Nutritional Biochemicals Corp.), 5 per cent. (w/v) $10 \mathrm{ml}$; Hartley's digest broth $20 \mathrm{ml}$; foetal calf serum (heated at $56^{\circ} \mathrm{C}$ for $30 \mathrm{~min}$.) $20 \mathrm{ml}$; glucose, 50 per cent. (w/v) $2 \mathrm{ml}$; calf thymus DNA (B.D.H.-highly polymerised), $0 \cdot 2$ per cent. (w/v) $1 \mathrm{ml}$; penicillin, 200,000 IU per ml, $0.5 \mathrm{ml}$; thallium acetate, 5 per cent. (w/v) $0.5 \mathrm{ml}$; phenol red, 1 per cent. (w/v) $0.2 \mathrm{ml}$.

These solutions were made in glass-distilled double-deionised water. The $p \mathrm{H}$ was adjusted to $7 \cdot 8$ with $\mathrm{N}-\mathrm{NaOH}$. Solid medium (GS agar) was prepared by the addition of

Received 18 June 1969; accepted 25 July 1969.

J. MED. MICROBIOL.-VOL. 3 (1970) 
0.65 per cent. agarose to the appropriate broth medium. Modifications of this medium were used for particular purposes as indicated in the text.

Tests were carried out in the acellular fluid or solid media for M. suipneumoniae described by Goodwin et al. (1967), which will be referred to as the Cambridge media. Cambridge broth differs from GS broth in containing pig serum and yeast extract but not foetal calf serum or calf thymus DNA, and in the absence of added glucose. The corresponding solid medium is made by the addition of Oxoid Ion Agar to Cambridge broth.

Isolation procedure. Pieces of lung from a pneumonic area when this was present (about $\left.0.5 \mathrm{~cm}^{3}\right)$ were triturated in $5 \mathrm{ml}$ phosphate-buffered saline $(p \mathrm{H} \mathrm{7.4)}$ and serial ten-fold dilutions were prepared; $0.2 \mathrm{ml}$ quantities were inoculated into $1.8 \mathrm{ml}$ amounts of GS broth. The inoculated broths were incubated at $37^{\circ} \mathrm{C}$ for at least $3 \mathrm{wk}$ and were examined at intervals for evidence of growth, as indicated by an acid change in $p \mathrm{H}$. A drop of culture from each of the tubes in which such a colour change occurred was plated on GS agar, which was examined microscopically for colonies during a similar period of incubation. Solid media were incubated in a mixture of 5 per cent. $\mathrm{CO}_{2}$ in nitrogen.

Staining methods. Films prepared from centrifuged deposits of broth cultures $(25,000 \mathrm{~g}$ for $30 \mathrm{~min}$.) were fixed in methanol and stained for $2 \mathrm{hr}$ at $56^{\circ} \mathrm{C}$ with Giemsa's fluid, used at a 1 in 15 dilution in tap water.

Colonies on solid media were stained and examined in situ by Dienes' method as described by Madoff (1960).

Satisfactory whole-colony preparations were obtained by the agar-fixation method of Klieneberger (Klieneberger-Nobel, 1962, p. 31), as adapted for routine use by the Mycoplasma Reference Laboratory (Bouin fixation, followed by staining with 1 in 50 Giemsa for $45 \mathrm{~min}$. at $56^{\circ} \mathrm{C}$ ).

Estimation of number of viable organisms. The titre of viable organisms was estimated by means of a colour-change test in which serial ten-fold dilutions of suspensions were prepared in 2-ml volumes of GS or Cambridge broth. The colour change end-point titre (CCT) was taken as the highest dilution of culture that gave a colour change when a volume of $0.2 \mathrm{ml}$ was seeded into $1.8 \mathrm{ml}$ of GS broth and tubes were incubated at $37^{\circ} \mathrm{C}$ for $3 \mathrm{wk}$.

Preparation of specific antiserum. Rabbit antiserum was prepared against a chosen prototype strain no. 462/2. This strain had been purified by 3 successive subcultures from single colonies (see Results). Organisms were grown in $300 \mathrm{ml}$ of a modified GS liquid medium in which Hartley's digest broth and calf serum were replaced by rabbit meat infusion and rabbit serum respectively. After centrifugation at $40,000 \mathrm{~g}$ for $20 \mathrm{~min}$., the deposit was washed once in veronal-buffered saline and, after recentrifugation, suspended in the same buffer. One-quarter of this material was mixed with an equal volume of 4 per cent. sodium alginate containing $0 \cdot 8$ per cent. calcium gluconate (Medical Alginates Ltd, Wadsworth Road, Perivale, Middlesex, England) and inoculated intramuscularly at 2 different sites. One-third portions of the remainder of the suspension were inoculated intravenously, without adjuvant, 2, 3 and $4 \mathrm{wk}$ later. Serum obtained $1 \mathrm{wk}$ after the last injection was satisfactory for metabolic inhibition tests, but not for growth-inhibition tests. A further series of 3 intravenous injections of material prepared in a similar manner was given $3 \mathrm{mth}$ later, and the serum subsequently obtained reacted strongly with the homologous strain no. $462 / 2$ in growth-inhibition tests.

Growth-inhibiting antiserum for $M$. bovirhinis was prepared by a similar procedure. Antisera for other mycoplasmas were mainly those used routinely for identification of mycoplasmas in the Mycoplasma Reference Laboratory. The details relating to these sera are described elsewhere (Leach, to be published).

Serological identification of strains. Strains were examined serologically by the paper disk growth-inhibition (GI) technique (Clyde, 1964) on GS agar, and by the metabolic inhibition (MI) technique (Taylor-Robinson et al., 1966) in GS broth.

Filtration. Two slightly different methods were used to estimate the order of size of the minimal viable particles by filtration through Millipore membrane filters (Millipore Filter Corp., Bedford, Mass., USA) of varying nominal pore diameters (p.d.). 
NEW MYCOPL ASMA FROM CALF LUNGS

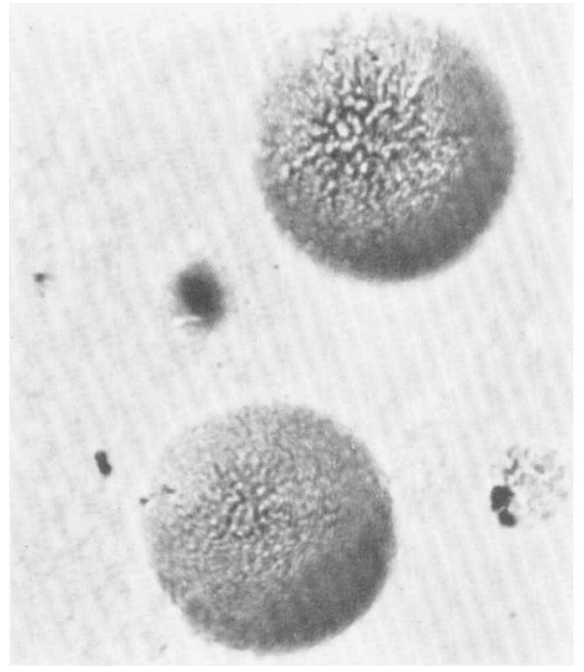

Fig. 1.-Colonies of recently isolated strain of "atypical" mycoplasma. Oblique transmitted light. Glucose calf-serum (GS) agar. Unstained. $\times 100$.

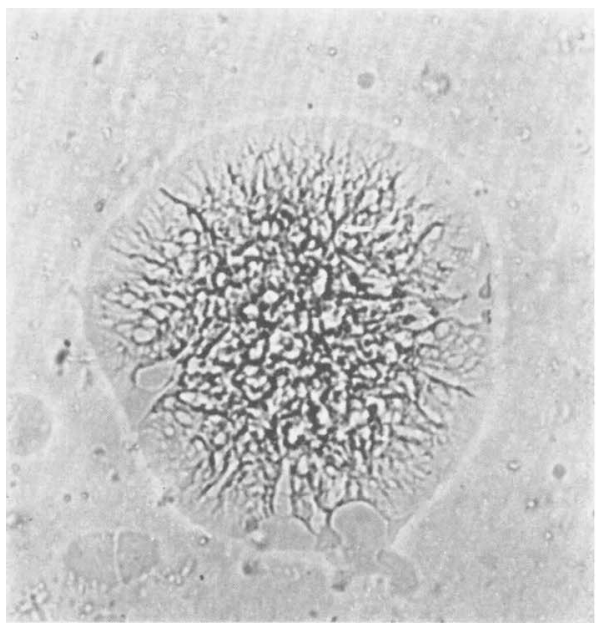

FIG. 3.-Colonies of recently isolated strain. Transmitted light. Cambridge agar. Unstained. $\times 180$.

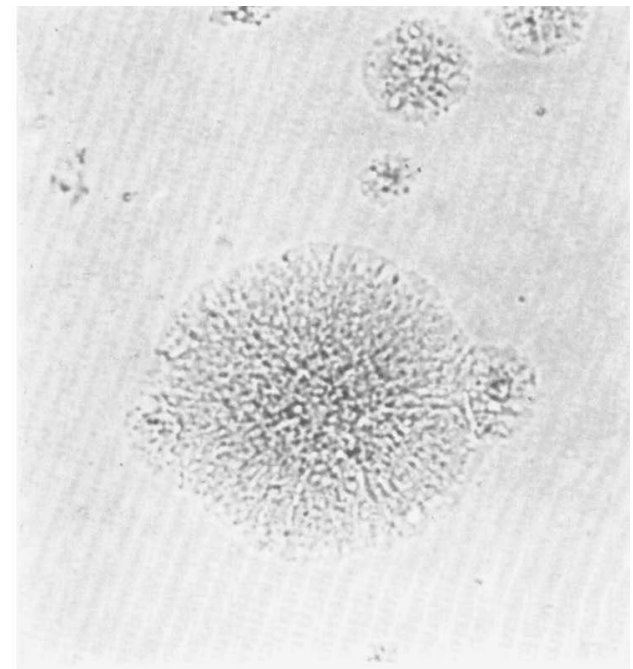

FiG. 2.-Colonies of recently isolated strain. Transmitted light. GS agar. Unstained. $\times 200$.

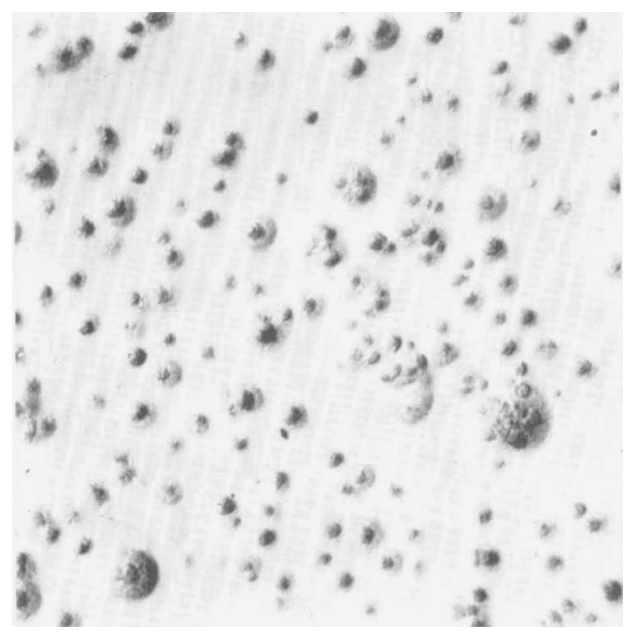

FIG. 4.- "Centre-forming" colonies. Oblique transmitted light. GS agar. Unstained. $\times 70$.

FIGs. 1-4.--The strain illustrated in these and subsequent figures is no. $462 / 2$. 


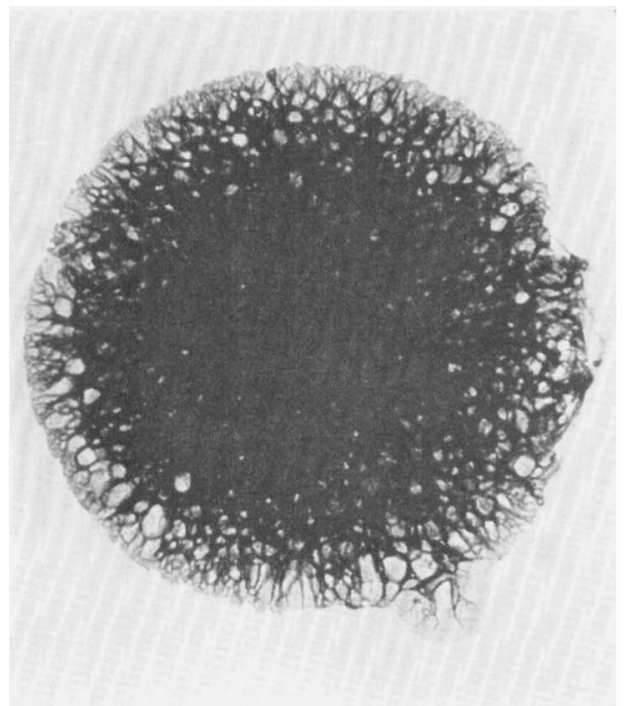

FIG. 5.-Large colony without "centre". Wholecolony preparation. Cambridge agar. Giemsa. $\times 120$.

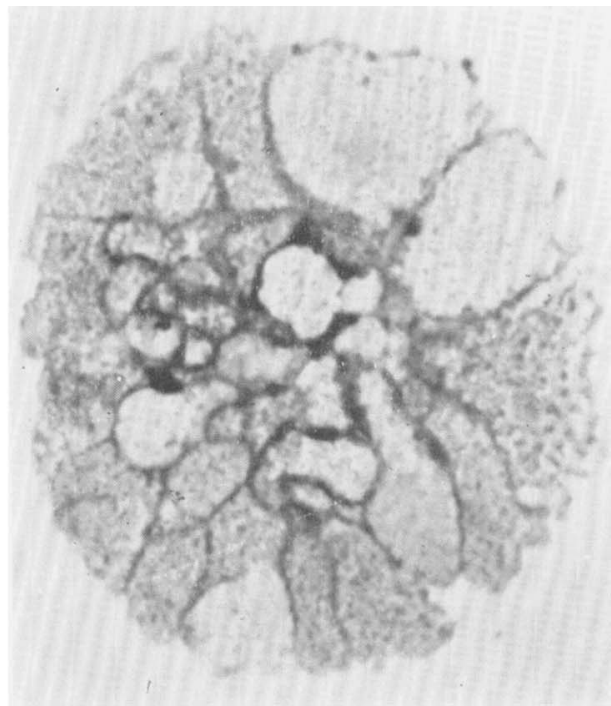

FIG. 6.-Small colony without "centre". Wholecolony preparation. Cambridge agar. Giemsa. $\times 1330$.

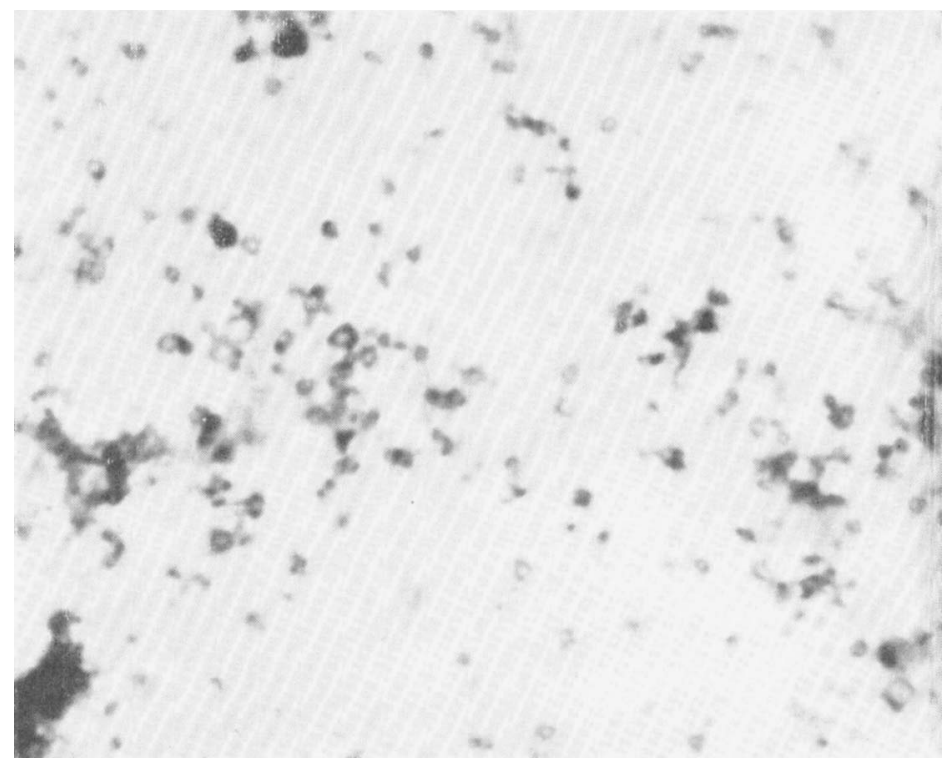

FiG. 7.-Light micrograph. Centrifuged deposit of culture in Cambridge broth. Giemsa. $\times 2000$. 


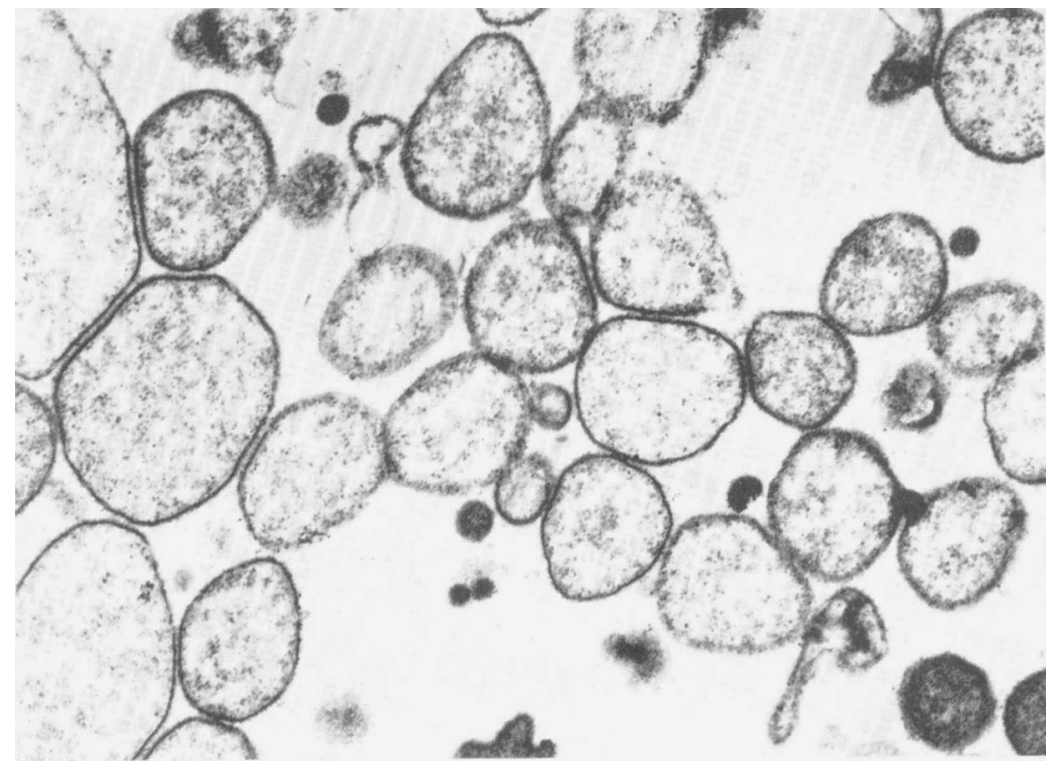

Fig. 8.-Electron micrograph. Section of centrifuged deposit of GS broth culture. $\times 23,000$.

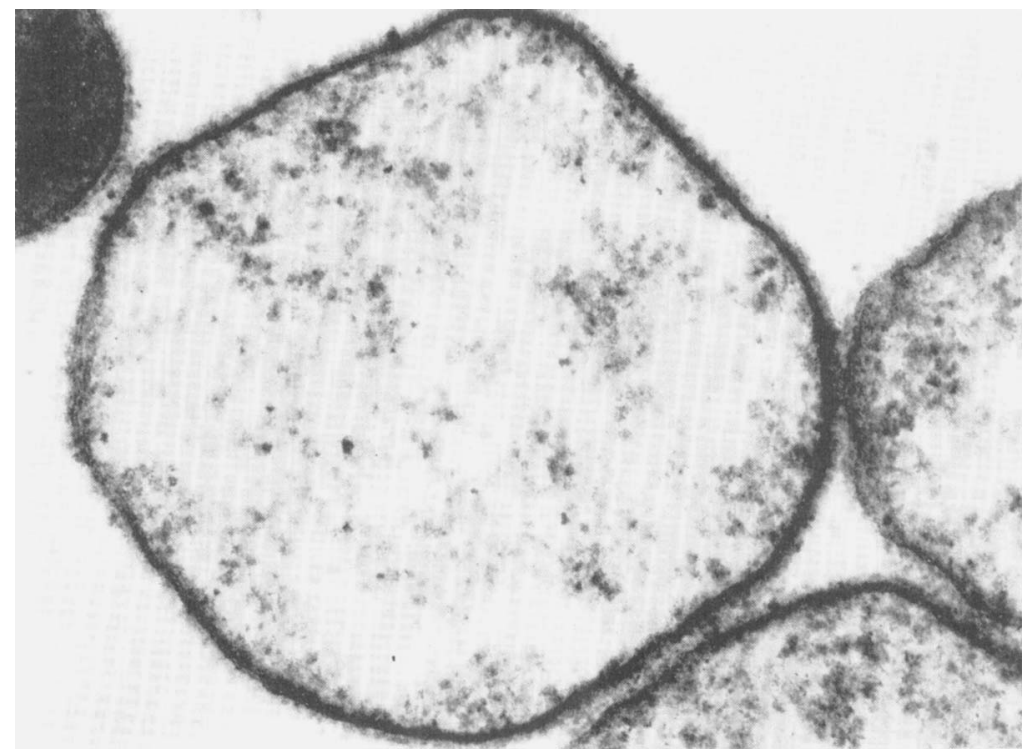

FIG. 9.--Electron micrograph. Section of centrifuged deposit of GS broth culture. $\times 83,700$. 
(a) At Compton (experiment A), the organisms were grown in GS broth that had previously been filtered through a membrane of $220 \mathrm{~nm}$ p.d. Separate portions of each test culture were passed through filters of 650,450 and $220 \mathrm{~nm}$ p.d. under a positive pressure of $5 \mathrm{lb}$. per sq. in. (c. $33 \mathrm{kN}$ per $\mathrm{m}^{2}$ ). Ten-fold dilutions of the filtrates were titrated in GS broth.

(b) At the Mycoplasma Reference Laboratory (experiment B), the test organisms were first grown for several subcultures in Cambridge medium. Portions of cultures were passed through 800 and $450 \mathrm{~nm}$ p.d. membranes in Swinney-type adapters attached to hypodermic syringes operated manually. The conditions were partially standardised by adjustment of the rate of flow through the filter to about one drop per second and by discarding approximately the first $1 \mathrm{ml}$ of filtrate. Titrations of filtrates were carried out in Cambridge broth.

Electron microscopy. Organisms were grown in $500 \mathrm{ml} \mathrm{GS}$ broth and then deposited by centrifugation at $25,000 \mathrm{~g}$ for $30 \mathrm{~min}$. The deposit was re-suspended in phosphatebuffered saline $(p \mathrm{H} \mathrm{7 \cdot 3)}$ and recentrifuged. The resulting pellet was prepared for electronmicroscope studies as described by Anderson and Barile (1965) and was embedded in Araldite. Sections were cut with a Reichert OMU2 ultramicrotome, stained with uranyl acetate and lead citrate and examined with an A.E.I. EM6 electron microscope.

Deoxyribonucleic acid (DNA) base composition. The strain no. $462 / 2$ was grown in 5 litres of GS broth containing pig serum instead of foetal calf serum, and the organisms were collected by centrifugation at $10,000 \mathrm{~g}$ for $30 \mathrm{~min}$. The DNA was extracted by the method of Marmur (1961) and its base composition was estimated from the "melting temperature" $\left(T_{m}\right)$ in standard saline citrate (Marmur and Doty, 1962). Both the DNA extraction and base composition estimation were kindly carried out by Mr L. R. Hill.

\section{RESULTS \\ Isolation of mycoplasmas from calf lung}

Strains isolated by means of glucose calf-serum (GS) broth. Samples from 72 pneumonic calf lungs, 20 healthy calf lungs and 10 healthy adult cow lungs were inoculated into GS broth. Negative results were obtained with all samples from healthy animals, but 49 out of the 72 suspensions prepared from pneumonic lungs produced evidence of growth (acidification) in GS broth cultures (table I). Primary cultures showing colour change were subcultured on GS agar and also on blood, chocolate and MacConkey agar plates to exclude the presence of bacteria. No bacterial growth occurred on any of these media, but in each case minute colonies developed on GS agar. The colonies were of two distinct and easily recognisable types. One type (described as " typical " in table I) consisted of " fried-egg" colonies similar to those produced by many mycoplasma species. The 18 isolates that formed this type of colony were all identified as $M$. bovirhinis. The other type of colony (described as " atypical " in table I), which was cultivated from 36 samples, had a granular or sometimes "lacy" appearance and lacked a well-defined centre (figs. 1-3). The remainder of this paper is concerned mainly with strains producing this type of colony. These will be referred to as " atypical " strains.

"Atypical " strains were present in lung suspensions at titres (CCT) ranging from $10^{2}$ to $10^{7}$ or greater, but in most cases the titres were between $10^{3}$ and $10^{5}$.

In 5 cases (table I) both " atypical" strains and M. bovirhinis were isolated from the same sample. $M$. bovirhinis generally grew to maximum titre within 3 days, but the " atypical" strains grew more slowly; when both were isolated from the same lung suspension the "atypical" strains were the more numerous 
and, although overgrown by $M$. bovirhinis in broth inoculated with more concentrated lung suspensions, were easily isolated in pure culture from the broths inoculated with higher dilutions.

Most of the isolations shown in table I were confirmed by subsequent repetition of the cultures from lung material that had been stored at $-70^{\circ} \mathrm{C}$.

\section{Isolation in medium without penicillin or thallium acetate}

To eliminate the possibility that the "atypical" strains might be L-phase bacteria ( $\mathrm{L}$ forms) induced by the presence of known bacterial inhibitors in the media, further portions of three lung emulsions from which these organisms

TABLE I

Isolation of mycoplasmas from bovine lungs by means of glucose-serum broth

\begin{tabular}{l|c|c|c|c}
\hline \multicolumn{1}{c|}{ Source } & \multicolumn{3}{|c}{ Number of lungs } \\
\hline examined & $\begin{array}{c}\text { civing broths } \\
\text { showing colour } \\
\text { change }\end{array}$ & $\begin{array}{c}\text { giving mycoplasma colony } \\
\text { types classified as }\end{array}$ \\
\hline $\begin{array}{l}\text { Pneumonic lungs of calves } \\
\text { Normal lungs of calves }\end{array}$ & 20 & 49 & $18^{*}$ & $36^{*}$ \\
Normal lungs of cows & 10 & 0 & 0 & 0 \\
\hline
\end{tabular}

* From 5 lungs both colony types were isolated.

had been isolated were cultured in GS medium from which the penicillin and thallium acetate had been omitted; similar organisms were again isolated. Each of these strains was subsequently subcultured several times in media free of these substances without any change in its cultural and colonial characteristics. The three strains were subsequently shown to be serologically indistinguishable from the chosen prototype "atypical" strain, no. 462/2 (see next section). The latter strain was itself subcultured for six passages in GS media free of penicillin and thallium acetate without evidence of reversion to bacterial forms. One of the three calves from which isolations were made in medium free from penicillin and thallium acetate had been treated earlier with neomycin, but the treatment had ended nearly $6 \mathrm{wk}$ before the lung was examined. It was not certain whether the second of these calves had ever received antibiotics, but the third calf had been raised at Compton and was known not to have had antibiotic treatment at any stage of its life.

\section{Properties of " atypical" strain}

It was apparent at an early stage that all "atypical" strains were indistinguishable in their general cultural characteristics. Subsequently, one strain, 
no. 462/2, was chosen as representative of the group for detailed examination. The following description applies specifically to this strain, but was confirmed where indicated by additional observations on other " atypical " strains.

Cultural and colonial characters. During primary isolation of " atypical " strains, growth was usually detectable in GS broth within 7-14 days (maximum range 4-23 days) of inoculation. Laboratory-adapted strains grew somewhat faster and growth from minimal inocula was usually detectable within 2 wk. Growth was indicated by an acid shift of $p \mathrm{H}$ accompanied by development of a slight, usually granular, deposit. "Atypical" strains grew poorly or not at all in conventional mycoplasma media. Plating of cultures on 5 per cent. ox-blood agar led after incubation to the production of an area of haemolysis under the inoculated area, but no growth was visible.

Early subcultures on GS agar produced mainly large colonies, up to $1 / 3 \mathrm{~mm}$ in diameter after 1-3 days' incubation. These colonies were roughly circular, although sometimes slightly uneven, and rather granular in appearance. They lacked the "centres" characteristic of most mycoplasmas (figs. 1 and 2) and did not penetrate the agar. They were friable in texture and disintegrated easily when touched. On Cambridge agar the colonies were generally similar, but had a more obviously "lacy" or reticulated appearance when viewed by transmitted light (fig. 3). Colonies of the above types could not be subcultured by means of a wire loop, but subcultures were successful when an agar block bearing colonies was transferred to broth or spread over agar medium. Usually a heavy inoculum was required for growth on the agar media, which were therefore unsuitable for titration of suspensions by means of colony counts. On the other hand, subculture from broth to broth was usually possible with inocula diluted at least to $10^{-7}$.

After several passages of strain no. $462 / 2$ in GS broth, the colonies on GS agar were found to have a different morphology, and at this stage a comparable broth culture produced many more colonies than previously. Colonies were then small, up to about $0.1 \mathrm{~mm}$ in diameter, and many possessed poorly defined centres which, nevertheless, penetrated the agar (" centre-forming colonies"; fig. 4). At this stage, 3 successive subcultures were made from single colonies. This cloned strain was used for the preparation of an antiserum in rabbits. Centre-forming colonies have not yet been observed on Cambridge agar.

The ability to produce small centre-forming colonies was temporarily lost after storage at $-70^{\circ} \mathrm{C}$ for a few months, but reappeared after further passages of the strain in broth. Most other "atypical" strains also produced centreforming colonies after several subcultures in broth and some were cloned in the same way as was strain no. 462/2. Other strains were cloned before they produced centre-forming colonies transferable with a wire loop; this was carried out by transferring into broth an agar block containing a single colony and repeating the procedure twice.

Microscopic examination. Both types of colony produced by the $462 / 2$ strain on GS agar were stained blue in situ by Dienes' stain. When impression films of colonies on Cambridge agar were stained by the Giemsa method, they were seen to consist mainly of enlarged forms, giving the whole colony a 
"vacuolated" texture (fig. 5), corresponding somewhat to the " lacy" appearance seen by direct observation. Under higher magnification the enlarged forms at the periphery of large colonies appeared to contain many particles, but these were more easily seen in small colonies as in fig. 6. As seen already with unstained preparations (fig. 2), colonies on GS agar stained with Giemsa had a less reticulate structure than those on Cambridge agar.

Smears were prepared from the deposit produced by centrifuging broth cultures of strain no. $462 / 2$ at $25,000 \mathrm{~g}$ for $30 \mathrm{~min}$. When stained with Giemsa, they showed pleomorphic organisms, the majority of which were ring forms of varying diameter up to about $1500 \mathrm{~nm}$ when measured with an ocular micrometer, but there were also many signet-ring and bipolar forms (fig. 7). In some preparations there were also smaller granular forms and occasional short filaments.

Electron-microscopic examination. Thin sections were prepared from pellets of centrifuged cultures of strain no. $462 / 2$ and two other cloned strains. When examined with the electron microscope at low magnification, the predominant forms were coccoid and varied in diameter between about 500 and $1500 \mathrm{~nm}$ (fig. 8). In addition, there were many somewhat smaller bodies and also some very small particles about $150-200 \mathrm{~nm}$ in diameter. The density of the internal structure varied according to the size of the particles, the smallest forms being the most dense. When viewed at higher magnification, the bodies were seen to possess a triple-layered cell membrane, but none showed any evidence of a cell wall (fig. 9). Some showed an outer " fringe" of amorphous material, somewhat similar to that seen in negatively stained electron micrographs of recognised mycoplasmas (Reuss et al., 1967).

Metabolic characteristics. No. $462 / 2$ and two other cloned strains were examined for their ability to grow without serum. Broth cultures were titrated in GS broth with and without serum and, after appropriate periods of incubation, the presence of growth was assessed by noting colour change in the broth cultures and by plating from appropriate tubes on GS agar. No growth was obtained at any dilution from the broths lacking serum, whereas growth occurred to a titre of $10^{9}$ in the broths with serum. These strains also failed to grow on GS agar when serum was omitted from the medium.

In contrast with their ready growth at $33^{\circ}-37^{\circ} \mathrm{C}$, the same strains failed to grow when inoculated into GS fluid or on solid GS media and incubated at $22^{\circ} \mathrm{C}$.

In a modified GS broth that contained no added glucose and in which glucose had been omitted from the Hanks' solution, no. 462/2 and the two other test strains grew well and produced a slight reduction in $p H$. There was no detectable utilisation of arginine or urea by the three test strains when they were grown in glucose-free GS medium to which 0.1 per cent. of either substrate had been added. These cultures also showed a slight acid shift of $p \mathbf{H}$.

Filtration experiments. To determine the order of size of the minimal reproductive units of the " atypical " strains, cultures of no. 462/2 and two other cloned strains were filtered in parallel with a representative mycoplasma, $M$. laidlawii (PG8) and a representative bacterial L-phase organism, the stable $\mathrm{L}$ form of Streptobacillus moniliformis (L1). 
Two experiments were carried out (see Materials and methods). In one (experiment A) the organisms were grown in GS medium and in the other (experiment B) the medium used was Cambridge broth. Cultures were filtered through membranes of varying p.d. In each experiment, all organisms were

TABLE II

Effect of filtration on the titres of viable organisms in broth cultures of "atypical" strains of mycoplasma and other organisms

\begin{tabular}{|c|c|c|c|c|c|c|c|}
\hline \multirow{2}{*}{ Expt } & \multirow{2}{*}{ Organism and number } & \multirow{2}{*}{$\begin{array}{l}\text { Age of culture } \\
\text { (days) }\end{array}$} & \multirow{2}{*}{$\begin{array}{c}\log _{10} \text { titre }(C C T) \\
\text { before filtration }\end{array}$} & \multicolumn{4}{|c|}{$\begin{array}{l}\text { Reduction in } \log _{10} \text { titre after } \\
\text { filtration through membranes of p.d. }\end{array}$} \\
\hline & & & & $800 \mathrm{~nm}$ & $650 \mathrm{~nm}$ & $450 \mathrm{~nm}$ & $220 \mathrm{~nm}$ \\
\hline \multirow[t]{3}{*}{$\mathrm{A}^{*}$} & $\begin{aligned} & \text { Mycoplasma } 462 / 2 \\
& \mathrm{~V} 7 / \mathrm{A} / 1 \\
& \mathrm{D} 2 / \mathrm{A} / 3\end{aligned}$ & $\dagger$ & $\begin{array}{l}8 \cdot 5 \\
8 \cdot 0 \\
7 \cdot 5\end{array}$ & $\begin{array}{l}\cdots \\
\cdots \\
\cdots\end{array}$ & $\begin{array}{l}2 \cdot 5 \\
3 \\
3\end{array}$ & $\begin{array}{l}5 \\
6 \\
5\end{array}$ & $\begin{array}{l}>7 \cdot 5 \\
>7 \\
>6 \cdot 5\end{array}$ \\
\hline & Mycoplasma laidlawii PG8 & $\dagger$ & $10 \cdot 0$ & $\ldots$ & 0 & 0.5 & $6 \cdot 5$ \\
\hline & $\begin{array}{l}\text { Streptobacillus moniliformis } \\
\quad \mathrm{L} \text { phase }(\mathrm{L} 1)\end{array}$ & $\dagger$ & $6 \cdot 0$ & $\ldots$ & 0.5 & $1 \cdot 5$ & $>5$ \\
\hline \multirow[t]{4}{*}{$\mathbf{B}^{*}$} & Mycoplasma $462 / 2$ & $\begin{array}{l}1 \\
2 \\
4 \\
8\end{array}$ & $\begin{array}{l}7 \\
7 \\
8 \\
7\end{array}$ & $\begin{array}{l}0 \\
2 \\
2 \\
2\end{array}$ & $\begin{array}{l}\ldots \\
\ldots \\
\ldots \\
\ldots\end{array}$ & $\begin{array}{r}4 \\
>6 \\
7 \\
>6\end{array}$ & $\begin{array}{l}\ldots \\
\cdots \\
\cdots \\
\cdots\end{array}$ \\
\hline & $\mathrm{D} 2 / \mathrm{A} / 3$ & 2 & 7 & 1 & $\cdots$ & $>6$ & $\cdots$ \\
\hline & Mycoplasma laidlawii PG8 & 1 & $\begin{array}{l}8 \\
9\end{array}$ & $\begin{array}{l}0 \\
0 \cdot 5\end{array}$ & $\begin{array}{l}\cdots \\
\cdots\end{array}$ & $\begin{array}{l}0 \\
2\end{array}$ & $\ldots$ \\
\hline & $\begin{array}{l}\text { Streptobacillus moniliformis } \\
\quad \mathrm{L} \text { phase }(\mathrm{L} 1)\end{array}$ & 2 & $\begin{array}{l}7 \\
5\end{array}$ & $\begin{array}{l}0 \\
1\end{array}$ & $\begin{array}{l}\ldots \\
\cdots\end{array}$ & $\begin{array}{l}2 \\
1\end{array}$ & $\ldots$ \\
\hline
\end{tabular}

* For experimental details see Materials and methods.

+ These GS cultures were filtered at a stage when a significant colour change had just appeared (usually 3-5 days).

grown, filtered and titrated in the same medium. The results of titrations of cultures before and after filtration are shown in table II.

In the case of the "atypical" strains no. $462 / 2$ and D2/A/3, filtration through $800 \mathrm{~nm}$ p.d. membranes caused a fall in titre of a hundredfold or less (experiment B); after filtration through $650 \mathrm{~nm}$ p.d. the fall was between one hundred and one thousandfold (experiment $A$ ). In both experiments, filtration through the $450 \mathrm{~nm}$ membrane caused the titre to drop by $10^{4}$ or more. Less than one-millionth of the titre remained after filtration through filters of $220 \mathrm{~nm}$ p.d. (experiment A). 
In contrast, the cultures of $M$. laidlawii and the L-phase organism passed the $800 \mathrm{~nm}$ and $650 \mathrm{~nm}$ filters with little loss of titre. The $450 \mathrm{~nm}$ filter caused reduction in titres of about a hundredfold or less, whilst the quantitative effect of the 220 nm filter was comparable with that obtained with the "atypical" strains.

With all these strains, filtration through membranes of decreasing nominal pore diameter caused a progressive diminution in titre. In this respect, the results were similar to those noted elsewhere for mycoplasmas and bacterial $\mathrm{L}$ forms, both of which are notably pleomorphic. Most viruses and bacteria, on the other hand, have a relatively uniform size, and show a much sharper "cut-out" effect around the limiting filter pore size (Van Boven, Ensering and Hijmans, 1968).

Serological studies. Antiserum prepared in rabbits against strain no. 462/2 was used in GI tests. The growth of 23 of the 36 available " atypical " strains was inhibited clearly by this antiserum and not by serum from an uninoculated rabbit. Fourteen of these strains, including no. 462/2, were also tested against $M$. bovirhinis antiserum with negative results. The strains reacting with no. 462/2 antiserum included cloned strains no. 462/2, D2/A/3 and V7/A/1. In addition to the above "atypical" strains, the three similar strains that had been isolated from lungs in medium free of penicillin and thallium acetate were also clearly inhibited by the no. $462 / 2$ antiserum. The serological identity of the 13 remaining " atypical" strains has not yet been determined.

The reactivity in GI tests of the " atypical " strains could often be enhanced by rapid passage in GS broth before testing. For most recently isolated strains the zone of inhibition caused by the no. $462 / 2$ antiserum was usually only slight or absent, and if present was seen only as a band of reduced colony size. After passage, a zone of definite inhibition was usually observed extending to 3-4 $\mathrm{mm}$ around the paper disk; this appeared to be correlated with the development of centre-forming colonies. The 13 unidentified strains are being examined and further passages may result in their being able to react with the no. $462 / 2$ antiserum in the GI test.

The serological relationship between strains no. 462/2, D2/A/3 and V7/A/1 was confirmed in MI tests with antiserum to strain no. 462/2, although the heterologous strains did not react to full titre. The homologous titre for this antiserum varied between 1 in 80 and 1 in 320 in individual tests. Strain no. D2/A/3 reacted at either full or half titre; strain no. V7/A/1 reacted at onehalf to one-eighth of the homologous titre. This degree of antigenic difference between serologically related strains was not unexpected and is consistent with our experience and that of other workers (Taylor-Robinson and Berry, 1969) using the MI test to examine a number of strains within a single species of Mycoplasma.

Further MI tests with strains no. $462 / 2$ and D2/A/3 were carried out against antisera to the 8 recognised mycoplasmas found in cattle (Leach), and to 17 other mycoplasma species. With the partial exception outlined below, all gave negative results (table III), indicating that strains no. 462/2 and D2/A/3 can be distinguished from known bovine mycoplasma species and from most 
of the commonly encountered mycoplasmas found in goats, pigs, dogs, rodents, poultry and man. The exceptional finding was that the two strains gave crossreactions with antisera to one strain of $M$. pulmonis (no. 880), but this was not confirmed with antisera to two other strains of $M$. pulmonis (strains Kon and Negroni) nor by a reciprocal test of $M$. pulmonis (strain no. 880 ) against antiserum to no. $462 / 2$.

TABLE III

Metabolic inhibition (MI) tests with "atypical" strains against antisera to recognised bovine and other mycoplasma species

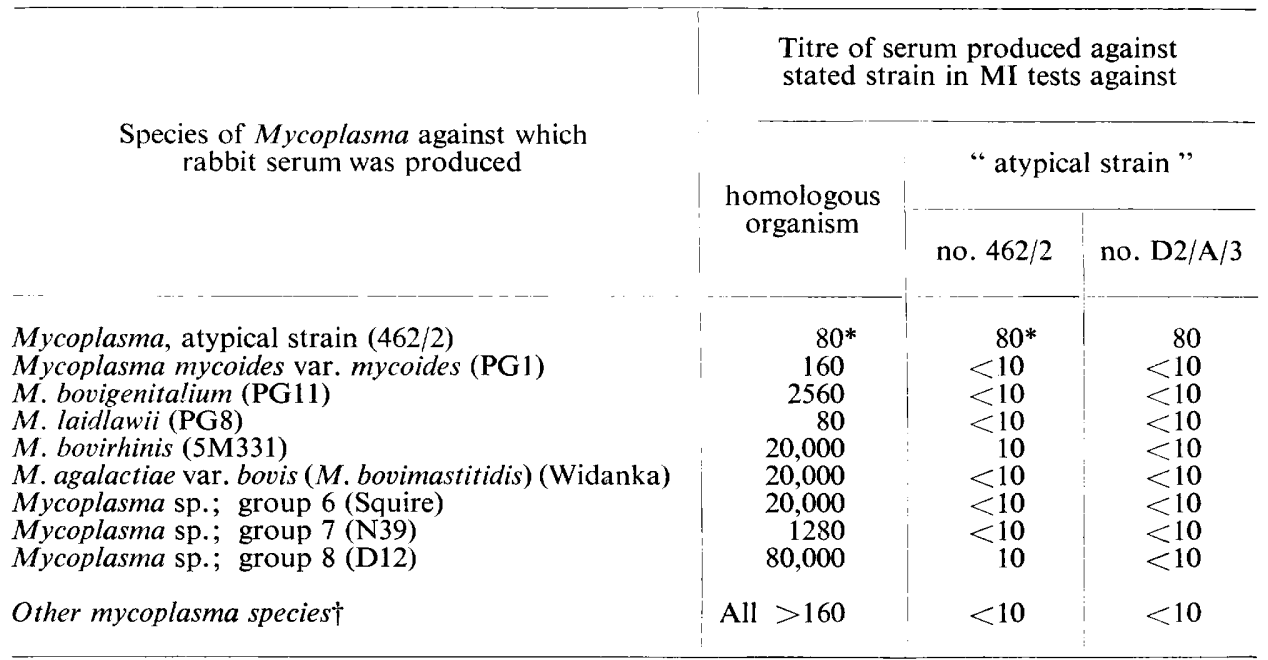

* Homologous titres up to 320 were obtained in tests other than those used for this table.

$\dagger$ The following strains were examined: $M$. pneumoniae (FH), M. fermentans (PG18), M. salivarium (PG20), M. orale type 1 (CH19219), M. orale type 2 (CH20247), M. hominis (PG21), M. arthritidis (PG6), M. neurolyticum (KSA), M. gallisepticum (X95), M. pulmonis (Kon; Negroni; see also text), M. gallinarum (PG16), M. synoviae (Lasswade), M. canis (PG14), M. spumans (PG13), M. hyorhinis (GDL), M. suipneumoniae (J), M. agalactiae (PG2), M. mycoides var. capri (PG3).

Deoxyribonucleic acid composition. Mr L. R. Hill reported that the DNA base composition of strain no. $462 / 2$, as determined from the " melting temperature " $\left(\mathrm{T}_{\mathrm{m}}\right)$ and expressed as moles per cent. guanine+cytosine (per cent. GC), was $28.5\left(\mathrm{~T}_{\mathrm{m}} 81 \cdot 0^{\circ} \mathrm{C}\right)$. A recognised Mycoplasma species ( $M$. mycoides var. capri; PG3) which was tested by the same method gave a value of 24 per cent. GC (Owen, Lapage and Hill, 1969), which conforms with other published findings for this species (Hill, 1966).

\section{Discussion}

Recent reports of the value of a special medium for the isolation of $M$. suipneumoniae prompted the use of a similar medium in attempts to isolate mycoplasmas from cattle. As a result, many exacting glucose-fermenting organisms were isolated from calf lungs in an enriched glucose calf-serum medium. These strains produced colonies on solid media that were somewhat 
atypical in comparison with those of most recognised mycoplasmas. They grew very poorly in conventional mycoplasma media and were easily differentiated from known mycoplasma species, including $M$. bovirhinis, which was also isolated from some lungs by the same methods.

The majority of " atypical " strains isolated were shown to be antigenically related by means of the growth and metabolic inhibition tests. Preliminary studies with three of these strains (Gourlay, unpublished observations) suggest that they also give almost identical electrophoretic patterns when examined by the polyacrylamide gel technique as used by Razin and Rottem (1967). The remaining unidentified strains are still being studied serologically.

The new type of organism is distinct from bacteria in its size, pleomorphism and lack of a cell wall, as demonstrated by stained films and electron micrographs. It also differs from most bacteria by being resistant to both penicillin and thallium acetate and in showing growth inhibition by specific antiserum in the absence of complement. These properties, together with a dependence on serum for growth, suggested that the new organisms were either mycoplasmas or bacterial L-phase organisms ( $\mathrm{L}$ forms). On the special agar media used, their granular or slightly "lacy" colonies were somewhat more reminiscent of L-forms than of mycoplasma colonies. This similarity was maintained in the failure of "atypical" strains to pass through Millipore filters of $450 \mathrm{~nm}$ p.d. without considerable loss of titre $\left(>10^{5}\right)$. Other observations made under the same conditions (Andrews and Leach, unpublished observations) confirmed those of Klieneberger-Nobel (1962, pp. 63-68), in that cultures of recognised mycoplasma species usually passed the $450 \mathrm{~nm}$ filter with little loss of viability, whereas the titres of several bacterial $\mathrm{L}$ forms suffered a much greater reduction (usually $>10^{3}$ ) than was observed for the Ll organism in the present tests. "Atypical" strains were actually less readily filtrable than the L-form when tested concurrently, but their filterability may be influenced to some extent by the tendency of the organisms to form clumps in the fluid media used.

Electron micrographs of no. $462 / 2$ and of two other strains revealed numerous particles, approximately $150-200 \mathrm{~nm}$ in diameter, with many other roughly spherical forms up to about $1500 \mathrm{~nm}$ in diameter. The dimensions and general morphology of these particles are similar to those often reported for mycoplasmas. The microscopic appearance of "atypical " strains in Giemsastained broth deposits, with " ring" and other pleomorphic forms predominating, are also characteristic of many mycoplasmas.

The strongest evidence that the new organisms are mycoplasmas rather than L-phase bacteria is that three strains, serologically and otherwise indistinguishable from the prototype strain no. $462 / 2$, were isolated without the use of antibacterial substances from the original lung material by inoculation directly into GS broth. One of these strains was from a calf that is known never to have been treated with antibiotics at any stage of life. In addition, none of these strains nor the prototype strain showed any evidence of reversion to bacterial forms after subculture in media free of bacterial inhibitors.

Further evidence in favour of the new isolates being mycoplasmas was provided by their DNA base composition. The figure of $28 \cdot 5$ per cent. GC 
obtained for the DNA base ratio for the prototype strain no. $462 / 2$ is outside the range quoted for Pasteurella, Corynebacterium, Escherichia, Streptococcus and Staphylococcus (Hill, 1966), the bacterial genera found in routine bacterial examinations of the lungs from which the " atypical" strains were also isolated. This figure is lower than those recorded for most bacteria (Hill) with the exception of the genus Spirillum and some Clostridium and Vibrio species, but is within the narrow range (26-32 per cent.) observed for recognised mycoplasma species so far tested (Bak and Black, 1968).

It is reasonable to conclude that, although they have some atypical characters, the organisms represented by strain no. $462 / 2$ form a new mycoplasma species. The serological studies suggest that this species is distinct from other mycoplasmas hitherto isolated from cattle and from all other recognised mycoplasma species so far tested.

In our experience the cultural and colonial characteristics of the " atypical " calf strains are similar to those of the pig mycoplasma, $M$. suipneumoniae. Although serologically distinct from $M$. suipneumoniae, the new species grows satisfactorily on media developed for the pig mycoplasma and poorly on conventional mycoplasma media. In our hands, both organisms were difficult to grow from small inocula, suggesting that further study of their growth requirements is needed. We have also isolated numerous strains with somewhat similar cultural characteristics from the respiratory tract of sheep. The relationship between these three groups is currently being studied at Colindale, and it can be said at this stage that they do not show cross-reactions in growth inhibition tests. Further work may be necessary to establish a final classification for the new calf strains, especially in view of recent proposals to subdivide the Mycoplasmatales into further taxonomic groups (Furness, Pipes and McMurtrey, 1968; Edward and Freundt, 1969). However, we would at present regard the " atypical " calf strains as forming a single new species of the genus Mycoplasma, within the existing family Mycoplasmataceae. We propose the name of Mycoplasma dispar for the new species and designate strain no. $462 / 2$ as the type strain. The specific epithet dispar was chosen to indicate the atypical characteristics of the species (" dispar": Latin adjective meaning "different" or "dissimilar"). A culture of strain no. 462/2 has been deposited in the National Collection of Type Cultures, Colindale, under the number NCTC10125.

The significance of the new mycoplasma species as a possible cause of calf pneumonia is unknown at present. Although these strains were isolated only from pneumonic and not from normal calf lungs, this was also true of $M$. bovirhinis. Moreover, many T-strain mycoplasmas were isolated from the same series of lungs on appropriate media (Gourlay, 1968). Experimental work on the pathogenicity of these mycoplasmas is in progress at Compton and will be reported separately.

\section{SUMMARY}

This paper describes the isolation and characterisation of a new mycoplasma species for which the name Mycoplasma dispar is proposed. Many strains of 
this glucose-fermenting organism were isolated in an enriched glucose calfserum medium from pneumonic lungs of calves, but not from healthy lungs of calves or cows. It could be isolated in medium free of known bacterial inhibitors, and when subcultured in this medium showed no evidence of reversion to bacterial forms.

The general characteristics of these strains were those of mycoplasmas; these included cultural and metabolic characters, morphological appearance in stained films and electron micrographs, growth inhibition by specific antiserum and a DNA base composition of 28.5 per cent. GC. However, the group showed some unusual features, including failure to pass readily through membrane filters of $450 \mathrm{~nm}$ pore diameter, poor growth in conventional mycoplasma media and production of atypical colonies on GS agar medium.

The serological identity of strains classified as $M$. dispar was demonstrated by growth and metabolic inhibition tests. They were serologically distinct from other recognised bovine mycoplasmas and from a wide range of mycoplasmas from other sources.

We wish to thank Mr L. R. Hill, National Collection of Type Cultures, Central Public Health Laboratory, Colindale, London, N.W.9, for carrying out the DNA extraction and base-composition estimation, Miss J. Bruce for the electron micrographs, $\mathrm{Mr}$ I. Jebbett for the photographs used in figs. 1 and 4 and Miss Sara Wyld and Mr P. G. Bradley for technical assistance. We are also very grateful to Dr B. E. Andrews for preparing and photographing many of the preparations, including those used in figs. 2, 3, 5, 6 and 7, and for his advice regarding some of the experimental work and during the preparation of the paper.

\section{REFERENCES}

ANDERson, D. R., AND Barile, M. F. BAK, A. L., AND BLACK, F. T.

1965. J. Bact., 90, 180.

Chanock, R. M., Hayflick, L., AND BARILE, M. F.

ClYDE, W. A.

1968. Nature, Lond., 219, 1044.

1962. Proc. Natn. Acad. Sci., USA, 48, 41.

$\cdot \quad \cdot \quad \cdot \quad$ 1964. J. Immun., 92, 958

Davies, G. . . . . . . . 1967. J. Comp. Path. Ther., 77, 353.

Edward, D. G. FF., AND Freundt, E. A. 1969. J. Gen. Microbiol., 57, 391.

Furness, G., Pipes, Florence J., and 1968. J. Infect. Dis., 118, 7. MCMURTREY, M. J.

Goodwin, R. F. W., Pomeroy, ANNetTe P., AND Whittlestone, P.

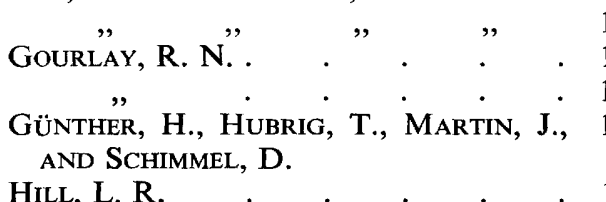

KLIENEBERGER-NOBEL, EMMY

LEACH, R. H.

MADOFF, SARABELle

MARE, C. J., AND Switzer, N. P. .

MARMUR, J.

MARMUR, J., AND DOTY, P. .
1965. Vet. Rec., 77, 1247.

1967. J. Hyg., Camb., 65, 85.

1968. Res. Vet. Sci., 9, 376.

1969. Vet. Rec., 84, 229.

1967. Arch. exp. VetMed., 21, 7.

1966. J. Gen. Microbiol., 44, 419.

1962. Pleuropneumonia-like organisms (PPLO): Mycoplasmataceae, London and New York.

1967. Ann. N.Y. Acad. Sci., 143, 305.

1960. Ibid., 79, Art. 10, p. 383.

1965. Vet. Med., 60, 841.

1961. J. Molec. Biol., 3, 208.

1962. Ibid., 5, 109. 
Owen, R. J., Lapage, S. P., AND Hill, 1969. Biopolymers, in press.

L. R.

RaziN, S., AND RotTem, S. . . . . 1967. J. Bact., 94, 1807.

Reuss, K., Plescher, C., Hulser, D., AND 1967. Zentbl. Bakt. ParasitKde, Abt. 1, Orig., HeRZBERG, K. 203, 121.

Taylor-Robinson, D., Purcell, R. H., 1966. J. Hyg., Camb., 64, 91. WONG, D. C., AND CHANOCK, R. M.

TAYLOR-RobinSON, D., AND BERRY, D. M. 1969. J. Gen. Microbiol., 55, 127.

Van Boven, C. P. A., Ensering, Hen- 1968. Ibid., 52, 403. RIETte L., AND HiJMans, W. 